\title{
Review
}

\section{Tuberculosis in Saudi Arabia: the journey across time}

\author{
Sahal Al-Hajoj, Bright Varghese \\ Mycobacteriology Research Section, Department of Infection and Immunity, King Faisal Specialist Hospital and \\ Research Centre, Riyadh, Saudi Arabia
}

\begin{abstract}
Saudi Arabia is the third-largest Arab country with a moderate annual burden of tuberculosis. However, tuberculosis (TB) is among several infectious diseases that have not been brought under control, despite the government's considerable efforts. This is clearly evidenced by the ongoing transmission of several imported and indigenous clades of Mycobacterium tuberculosis. In addition, the country faces the threat from rising proportions of extrapulmonary TB, non-tuberculous mycobacterial infections, and drug resistance. Furthermore, the country falls behind the global targets set by World Health Organization for the success rate of TB treatment. The country needs more population-based research studies, centralized and easily accessible clinical data registries, and centralized research and diagnostic facilities. This review focused on the trends of mycobacterial infections and on future proposals to improve TB control measures in Saudi Arabia.
\end{abstract}

Key words: Saudi Arabia; tuberculosis; epidemiology; transmission dynamics; migrants.

J Infect Dev Ctries 2015; 9(3):222-231. doi:10.3855/jidc.5296

(Received 15 May 2014 - Accepted 15 October 2014)

Copyright $@ 2015$ Al-Hajoj et al. This is an open-access article distributed under the Creative Commons Attribution License, which permits unrestricted use, distribution, and reproduction in any medium, provided the original work is properly cited.

\section{Introduction}

Tuberculosis (TB) is a re-emerging infectious disease and a substantial public health problem globally despite improvements in diagnosis, treatment, and control. The 2012 global report showed a development of 8.6 million new cases and 1.3 million deaths related to TB, including 320,000 deaths among human immunodeficiency virus (HIV) co-infected patients. However, a fall in new TB cases and drop in mortality to $45 \%$ was noticed worldwide, despite of the challenges from drug resistance and HIV coinfection [1].

\section{Epidemiology of tuberculosis in Saudi Arabia}

Saudi Arabia is the third-largest country in the Middle East by land area, constituting the bulk of the Arabian Peninsula, and is the third-largest Arab country. As of 2012 statistical data, the total population is $29,195,895$, consisting of $19,838,448$ Saudi nationals and 9,357,447 non-Saudi nationals [2]. According to the World Health Organization (WHO), in 2012, Saudi Arabia reported an annual TB incidence rate of 18/100,000 population and remains a moderate TB burden country [1]. Figure 1 shows the changes in incidence rates of tuberculosis in the country since 2000 .
The published data show that TB in Saudi Arabia is still not fully controlled despite the government's efforts to eradicate the disease. Even though the directly observed therapy short course (DOTS) program in the country was implemented in 1999 as part of the national tuberculosis control program (NTP), the treatment success rate (62\%) still remains below the international target set by the WHO $(85 \%)$ [3]. In addition, the recent case detection rate also remains at $87 \%$ [1]. In the last 10 years, the mortality rates among $\mathrm{TB}$ patients in the country show a decreasing trend (7.2\% to 6.1\%) among Saudis and a steady state among non-Saudis $(\sim 5.4 \%)$. Nonetheless, advancing age and male gender are still risk factors for higher mortality among Saudi nationals, and being female is a risk factor among non-Saudis. In addition, HIV seropositivity, smear positivity, and previous history of TB treatment were also predisposing factors behind elevated mortality [4]. The incidence rate of TB is two or three times higher in the immigrant population compared with the local population [5]. Furthermore, annual statistical data from the Ministry of Health showed a declining trend of incidence among non-Saudis and a stable trend among Saudi nationals (Figure 2). 
Figure 1. Incidence rate of TB during 2000-2012 [5,8]

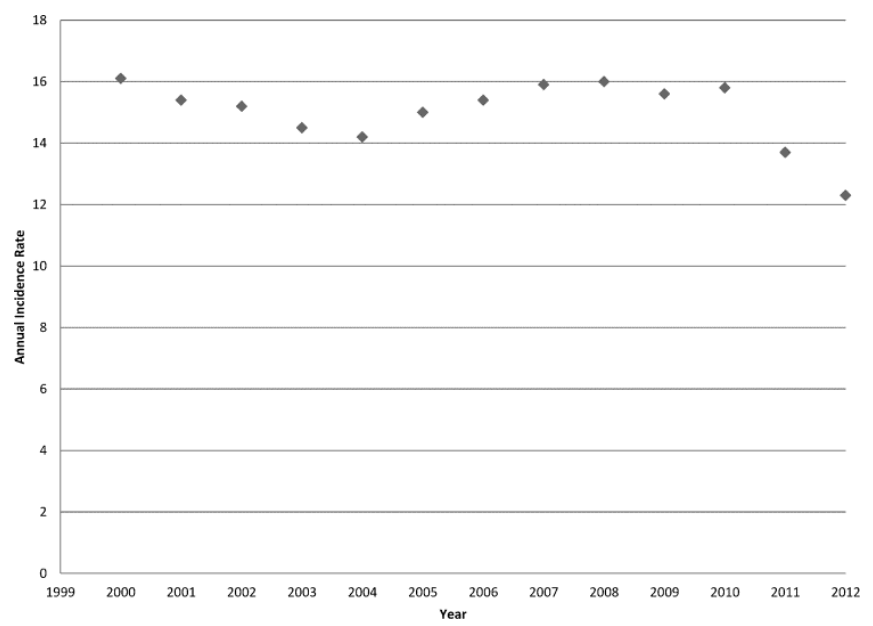

\section{Regional difference in annual TB case notifications}

Regional differences in the incidence rate of TB in the country have been clearly demonstrated in several studies [5-8]. Some regions showed a decrease in TB prevalence, whereas other regions with a high number of immigrants showed an increase in TB incidence [9]. Figure 3 shows the trend of reported TB cases during 2006-2012. Clear evidence of higher TB incidence in the western region, followed by the central region, has been observed during the last seven years. These two regions have the most populated provinces, hosting the majority of the immigrant population.

\section{TB in Gulf Cooperation Council (GCC) states and the Arabian Peninsula}

Among the GCC states, Saudi Arabia reports the highest number of notified cases annually. However, compared with the other five member states except United Arab Emirates and Oman, the real incidence rate for 100,000 population is low. Interestingly, extrapulmonary TB (EPTB) is reported in all these states above the level (> 25\%) of developed countries. The treatment success rate in Saudi Arabia is still behind the global target, though the other states have already reached the targets [1]. Generally, the Arabian Peninsula, which includes Iraq, Jordan, and Yemen along with the GCC states, has a moderate TB burden. However, Saudi Arabia remains at the seventh position only in terms of prevalence [1].

\section{Pulmonary TB and extrapulmonary TB}

Abouzeid et al. reported an increasing trend of pulmonary TB case notification in the past ten years in Saudi Arabia [5]. This study showed that smearpositive pulmonary $\mathrm{TB}$ is consistently reported
Figure 2. Tuberculosis incidence rate among Saudi and nonSaudi nationals during 2000-2009 [5]

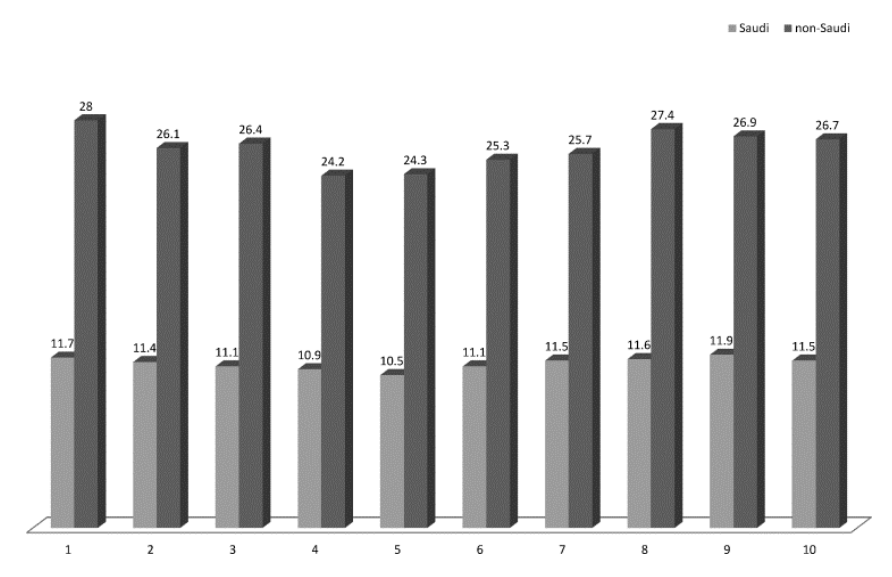

(44.9\%-50.2\%) in Saudi nationals, whereas immigrants showed considerably higher rates $(52.1 \%$ $62.6 \%$ ) than the global rate of $45.5 \%$. However, smear-negative pulmonary TB is found less frequently than in other global regions among Saudis and nonSaudis. The pulmonary smear-positive TB among both Saudis and non-Saudis showed an upward trend ( $11.8 \%$ to $20.2 \%$ ); this may indicate the impact of intensifying the diagnostic capabilities and other implementations done under the NTP [5]. However, the Ministry of Health of Saudi Arabia reported a decrease in pulmonary TB incidence in previous years (Figure 4).

Figure 3. Regional case notification of TB during 2006-2012 [8]

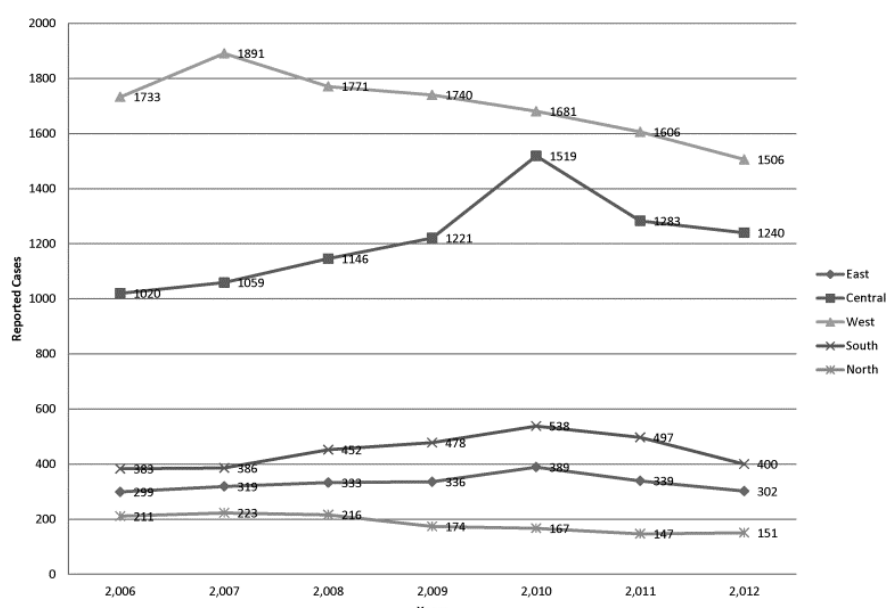

The notified new cases of $\mathrm{TB}$ in the five geographical regions representing 13 provinces of the country have been explained. The western region includes the provinces Makkah, Medina; the northern region includes Tabuk, Hail, Al-Jouf; the northern borders include South-Asir, Jizan, Najran and al-Baha; the central region includes Riyadh and Al-Qassim. 
In Saudi Arabia, the level of extrapulmonary TB (EPTB) is stable, $29.3 \%$ in 2006 compared to $28.4 \%$ in $2012[8,10]$. According to the WHO, the Eastern Mediterranean region (which includes Saudi Arabia) has the highest rate of EPTB (22\%) globally. In this context, Saudi Arabia always stays above the average (28\% in 2012) [1]. Saudi nationals show a significant predominance of EPTB compared with the immigrant population. The infection rate has always been above $50 \%$, but there was a clear rise (from $52 \%$ and $59.8 \%$ ) between 2006 and 2011 [8,10]. A recent retrospective analysis showed an upward trend of EPTB among Saudis (9\%), while non-Saudis showed a downward trend $(-17.2 \%)$ [5].

Another recent study conducted at King Faisal Specialist Hospital and Research Centre, Riyadh, on a nationwide data collection to determine the related demographical and clinical factors of EPTB showed a similar dominance of the autochthonous population in terms of incidence rate. This study revealed a domination of male $(57.5 \%)$ gender. This is distinctly different from the predominance of EPTB in the rest of the world. Apart from the predominance of TB in lymph nodes and central nervous and gastrointestinal systems, TB was largely reported, particularly among Saudi nationals. Nonetheless, a huge diversity in the clinical manifestations of EPTB in the country has been reported previously in various institutions [1113]. Figure 4 details the incidence rate of extrapulmonary TB for a period of eight years in the country, as reported by the Ministry of Health.

The reasons behind the higher incidence of EPTB in Saudi Arabia are still unknown. The same trend has also been found in all the neighboring countries [1,14]. According to the WHO, the Eastern Mediterranean region shows the highest incidence of EPTB in the world [1]. One possible assumption is that this high rate may related to the high probability of reactivation of latent infection, particularly among migrantreceiving countries [15]. On the other hand, another unexplored possibility is related to the host genetic factors, as all the Arab counties are prone to genetic disorders and related complications mainly because of the high rate of consanguinity.

\section{Factors influencing TB transmission in Saudi Arabia}

\section{Hajj and Umrah}

Hajj is the most sacred pilgrimage to Makkah followed by a visit to the other holy city, Medina. Hajj annually gathers approximately three million Muslims from around the world. Umrah is another Islamic
Figure 4. Incidence rate of pulmonary and extrapulmonary TB during 2005-2012 [8]

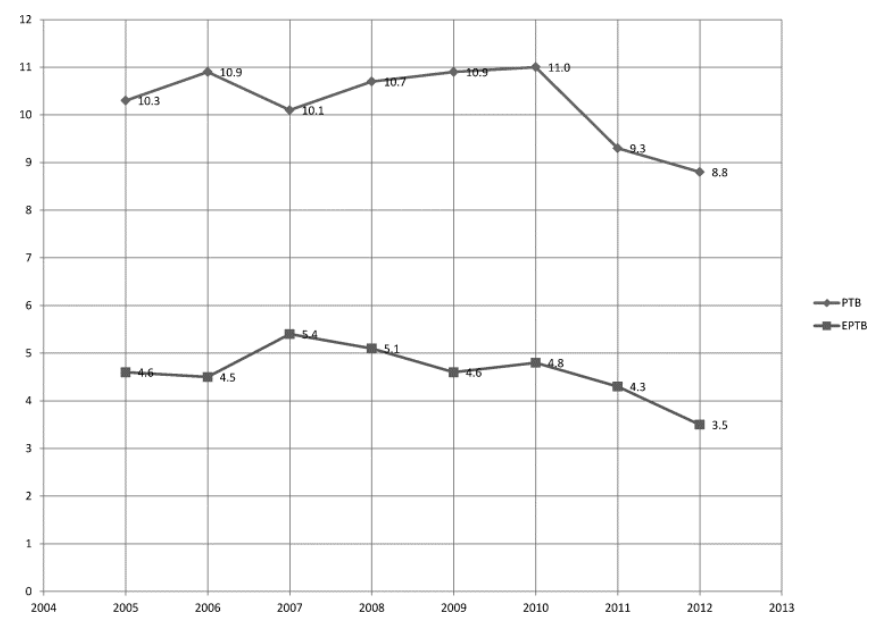

ritual, which can be performed throughout the year by visiting both holy cities; approximately five to seven million visitors arrive annually. The intense congestion of pilgrims, the majority of whom are from highly endemic places of TB in Asia and Africa, overcrowding, supports the transmission of infectious diseases, including TB [16-18]. Transmission is also influenced by the age of the pilgrims, who may be suffering from underlying diseases or conditions, and is exacerbated by the high level of physical exertion.

\section{Immigrants}

In addition to its 20 million citizens, Saudi Arabia hosts 9.9 million (32.4\% of the total population) immigrant workers from all over the world [2]. These immigrant workers are scattered all over the country and are concentrated in major cities, most originating from TB-endemic countries in Asia and Africa. In a recent study, the collated data from non-Saudi TB patients showed a higher presence of Africans (37.5\%), South Asians (27.8\%), and Southeast Asians $(23.5 \%)$, with a considerable threat imposed by the Yemeni migrants (11.14\%) [5]. In addition to the legal migrants, a large number of unaccounted illegal migrants are found in most of the provinces. The significance of this was shown in a recent study that reported that treatment defaulters of $\mathrm{TB}$ are mainly illegal migrants [19].

\section{Transmission dynamics of TB in Saudi Arabia}

To date, the published studies showed the distinct role of migrants in the transmission dynamics of TB in the country. Few recent studies have reported current TB transmission trends in the country. A study on 39 patients with multiple episodes of TB within an 18month period showed a trend of reactivation of remote 
infection eventually followed by an exogenous reinfection. The most striking finding was that $35.9 \%$ of the reinfection was caused by drug-resistant strains, including MDR-TB. This trend was most pronounced among the migrants from African countries [20].

Another study conducted on a nationwide collection of drug-resistant TB isolates showed the transmission cycle of TB in the country between the Saudi and non-Saudi patients to be highly admixed. The majority of drug-resistant strain clusters were shared between the Saudi and non-Saudi patients. There was little difference between the distribution of strain lineages in both local and immigrant groups. However, the highest ratio (59.5\%) of the shared strain clusters showed the typical social mixing of the resident populations [21].

Varghese et al. recently reported on the transmission of TB among the autochthonous and immigrant populations of the eastern province in Saudi Arabia, which has a large population of migrants [6].The recent transmission index in the region was $32.1 \%$. Of particular interest was the observation that $75.8 \%$ of the strain clusters were shared between indigenous and immigrant populations, particularly immigrants from Southeast Asia (40.7\%). In contrast, cross-national transmission among the immigrant groups was very limited $(24.2 \%)$. This study concluded that the socio-economical characteristics of the migrant group have a distinctive and detectable impact on the diversity of strain lineages and transmission dynamics of TB in the eastern province of Saudi Arabia [6].

\section{Molecular epidemiology of Mycobacterium tuberculosis in Saudi Arabia}

The Saudi Arabian resident population has a unique structure as it includes people from more than 100 countries, many from TB-endemic areas. This has a high impact on the phylogenetic composition of $M$. tuberculosis, as almost all the defined phylogenetic lineages have been identified from Saudi as well as non-Saudi patients.

The first nationwide study on molecular epidemiology of $M$. tuberculosis was conducted on 1,505 clinical isolates collected from seven provinces of the country during 2002-2005. The genotyping results revealed 387 individual genotype patterns, a clustering rate of $86.4 \%$, and 182 clusters containing between 2 to 130 isolates per cluster. A total of $94 \%$ of the strains matched to the spoligotype patterns in an international database. The majority of the isolates $(81 \%)$ were imported strains including the following clades: Central Asian (CAS, 22.5\%), ill-defined T clade (19.5\%), East African Indian (EAI, 13.5\%), Haarlem (7.5\%), Latin American Mediterranean (LAM, 7.2\%), Beijing (4.4\%), Manu (2.7\%), X $(0.9 \%)$, and Mycobacterium bovis $(0.9 \%)$. In addition, two clonal complexes were identified with unique spoligotyping signatures (octal codes 703777707770371, and 67777377413771), which were specific to Saudi Arabia [21].

Recently, Al-Hajoj et al. conducted a study on a nationwide collection of 902 isolates and reported the impacts of demographic factors on the trend of molecular epidemiology of TB. The findings revealed the same large diversity of $M$. tuberculosis, and that some strains (TUR, S, Ghana and Uganda-I) were found to be more prevalent among elderly ( $>65$ years) patients. The strain cluster ratio was relatively low $(12.5 \%)$ among the elderly group, whereas children $(<$ 15 years) showed the highest $(43.1 \%)$ ratio. The study finally concluded that the current population structure of M. tuberculosis in Saudi Arabia is highly diverse, with significant associations with demography, transmission dynamics, and origin of patients. The difference in genotype distributions among young and elderly patients reflects the ongoing change in the strain population structure in the country [22] (Figure 5).

Another retrospective analysis by Varghese et al. conducted on 524 isolates from the industrialized eastern province of the country showed the same large diversity of $M$. tuberculosis. This study also revealed a large diversity with 14 lineages, which were shared between autochthonous and immigrant populations [6].

Figure 5. Nationwide phylogenetic diversity of Mycobacterium tuberculosis [22]

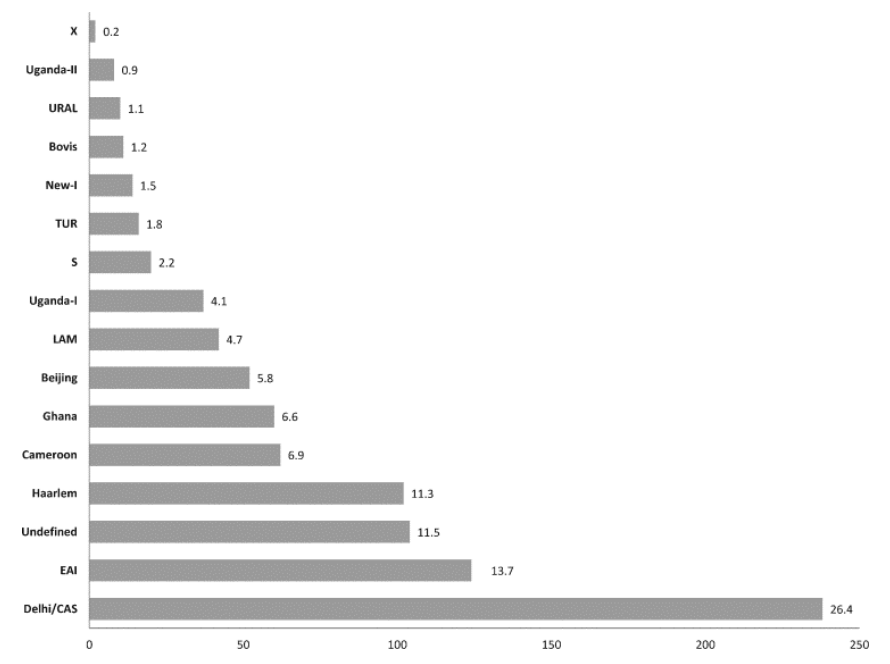




\section{Phylogenetic distribution of drug-resistant $M$. tuberculosis}

In 2013, Varghese et al., in a study of drugresistant isolates from a nationwide collection, found that 14 strain lineages are common among the Saudi resident population. Major lineages observed were Delhi/CAS (21.1\%), EAI (11.2\%), Beijing (11.2\%), and main branches of the Euro-American superlineage such as Ghana (14.9\%), Haarlem (10.6\%), and Cameroon (7.8\%). In addition, M. bovis BCG (4.6\%), Uganda-I (2.8\%), S (2.5\%), X (2.2\%), New I (1.5\%), and TUR $(1.5 \%)$ were also observed. Interestingly, a higher representation of lineages X, S, Haarlem, and M. bovis BCG were observed among Saudi nationals, whereas EAI, Beijing, Delhi/CAS, and Ghana were well defined among immigrants, even in the highly admixed nature of strain clustering [21].

\section{Epidemiology of drug-resistant tuberculosis in Saudi Arabia}

Few small-scale studies conducted in the country have reported the proportion of resistance to any firstline drugs ranging between $14 \%$ and $20 \%$, with MDRTB between $1 \%$ and 44\% [23-29]. These studies were retrospective analyses focused on specific categories of patient populations and did not follow any standard guidelines or quality control measures. Until 2013, the true burden of drug-resistant TB was not known, as the country never conducted a representative national survey to measure levels and patterns of anti-TB drug resistance. In 2013, Al-Hajoj et al. reported the results of the first nationwide drug surveillance survey conducted with a representative population of nationals and immigrant patients. This was the first study in the country conducted under the guidelines of the WHO with strict quality control analysis. A nationwide annual collection of 1,904 M. tuberculosis isolates from all the provinces were subjected to firstline drug susceptibility testing. The results were promising; a low level (4\%) of MDR-TB was found, whereas the rate of any drug resistance was found to be $23.6 \%$. Though the MDR-TB was low in prevalence, it was strictly confined to the western region of the country and was more predominant among immigrant workers [6].

Interestingly, large discrepancies in the reporting of drug susceptibility testing of $M$. tuberculosis were reported in the country, particularly in defining MDRTB. A recent study conducted with a nationwide collection of isolates showed discrepancies of $2.3 \%$ in defining MDR-TB between diagnostic laboratories around the country. Nonetheless, there was also a high level of strains falsely reported as resistant (36.3\%), and false susceptibility among the reports from the diagnostic laboratories was found to be $31.8 \%$. These finding shows that even though a common diagnostic technique is followed in all the laboratories, errors are still made. Moreover, the false-positive or falsenegative reporting has serious consequences for patient management [30].

\section{Molecular characterization of drug-resistant TB}

Recently, Varghese et al. investigated the diversity of mutations in both INH- and RIF-resistant $M$. tuberculosis isolates. High frequency of $r p o B$ codon 531 mutations $(67.1 \%)$ in RIF-resistant strains and kat $G$ codon 315 mutations $(65.2 \%)$ in INH-resistant strains were reported. In addition, mutation to inhA position -15 conferring INH resistance and codons 516,510 , and 526 of the rpoB gene were also observed. Mutations responsible for INH resistance, katG 315, and inhA position -15 were predominant among the newly diagnosed cases [31]. Another recent study on a nationwide collection of 415 INH- and RIFresistant isolates, to determine the diverse occurrence of mutations among local and migrant population, showed huge diversity of $r p o B, k a t G$, and inhA mutations, along with some unknown mutations. In addition, a statistically significant association between the geographical origin of the patients and the type of mutations observed were clearly evident. The autochthonous population showed a predominance of $r p o B$ codon 516 and 526 mutations. However, the inhA promoter position -15 and -8 mutations were more prominent among immigrants [32].

\section{HIV and TB in Saudi Arabia}

Despite the introduction of an HIV surveillance program in 1984, new incidences of the disease are increasing, particularly among Saudi nationals. The recently reported incidence rate is $<4$ cases $/ 100,000$ population [33]. The screening of HIV in TB patients has been sub-optimal in the country for decades $[6,34]$. In contrast, recent WHO statistics show that $89 \%$ of the total TB patients in the country had been screened for HIV, which is a promising result [1].

A study conducted on data collected over 10 years showed that the incidence of TB in people living with HIV in Saudi Arabia is 30 times higher compared to the general population. However, the number of people with HIV infection is relatively small, with only 217 people with HIV registered in the decade 
1997-2007, and only 16 (7.4\%) with TB co-infection. Seven developed extrapulmonary disease (44\%), six had pulmonary TB (37\%), while three had both (19\%). The incidence rate of TB was $1,354 / 100,000$ population among the HIV-infected cohort, with an incidence rate of pulmonary TB of 762/100,000 and extrapulmonary TB of 592/100,000 [35].

In the recent nationwide $\mathrm{TB}$ drug surveillance survey, only 17 patients with TB/HIV co-infection (< $1 \%$ of those enrolled) were observed, and the majority (53.7\%) of those enrolled had unknown HIV status [6]. The lack of association between drug resistance and HIV found in this study was therefore not surprising, as similar findings had been made previously [34]. Thus, this finding should not be considered conclusive because of the large proportion of patients with unknown HIV status [6].

Due to the unique sociocultural and religious context in Saudi Arabia and non-acceptance of individuals with HIV-related risk behaviors, a prevention program remains a challenge in the country. However, the Ministry of Health recently developed a five-year plan to reduce the death of HIV patients with $\mathrm{TB}$ by $50 \%$ in 2015. A long-term strategic plan is made and implemented with eight dedicated treatment facilities and diagnostic facilities in major cities. All Saudi nationals receive free treatment, and non-Saudis are usually deported to their countries if they are diagnosed to have HIV.

\section{Tuberculosis control program setup in Saudi Arabia}

The activities of National TB Control Program (NTP) of Saudi Arabia are integrated into the general healthcare facilities. A central TB unit in the Preventive Medicine Directorate of the Ministry of Health directs and supervises the program by making policies, monitoring, evaluating, training, and coordinating with the different levels of the governmental health system and other sectors involved in TB control activities. TB care services are integrated in general healthcare facilities mainly because of the social stigma accompanying TB in the country. The key players in the TB treatment are the two chest hospitals (nationwide referral centers for MDR-TB management) located in the central and western provinces, and other two TB centers with outpatient clinics in the eastern and western provinces. However, identification of TB suspects is performed at all levels of healthcare services by general practitioners and specialists. Diagnosis of TB patients and prescription of treatment is only performed in hospitals by specialists, while follow-up is undertaken in hospitals and by general practitioners in primary healthcare centers. Diagnosis of TB in the country is mainly based on sputum smear microscopy, radiography, mycobacterial culture, and histopathology. In addition, limited molecular techniques are available only in some referral laboratories.

Surveillance starts at the outpatient clinics and in primary healthcare centers by general practitioners. Patients suspected to have TB are listed in a suspect register and referred to nearby hospitals for diagnosis. An assigned coordinator in the same hospital is notified of confirmed TB patients. If there is no assigned coordinator, the infection control section is notified, which in turn notifies the district coordinator, using the adopted notification form. After notification, the district coordinator assigns the case a unique number in the TB register and informs the hospital coordinator of that number in order to label the patient's treatment card. Patients are given appointments by the treatment physicians for followup and smear examination. Smear microscopy results are kept in the patient's file and a copy is sent to the district coordinator to be recorded in the TB register. District coordinators submit a monthly case-based report to the central unit, including new and relapse patients, in addition to treatment outcome. Patients who default on treatment are traced and contacted by an outpatient clinic nurse and the district TB coordinator [5].

\section{Emergence of non-tuberculous mycobacterial infections in Saudi Arabia}

Non-tuberculous mycobacterial (NTM) infections are another emerging threat for developing as well as developed countries, even though they are opportunistic pathogens. The escalation of NTM infections is mainly related to HIV and other immunosuppressive illness [36]. Saudi Arabia is not an exception; recent studies have shown high potential of NTM infections in the country, even in immunocompetent individuals [37].

Varghese et al. recently demonstrated the huge species diversity of NTM for the first time in the country. This is a very different picture from that found in the Western world, where fast-growing species such as $M$. abscessus and $M$. fortuitum are more prevalent in causing clinically relevant pulmonary and extrapulmonary infections (Figure 6). This study reported for the first time the clinical relevance of the species $M$. celatum, M. xenopi, $M$. 
scrofulceum, M. lentiflavum, $M$. asiaticum, and $M$. simiae in the country. In addition, $62.1 \%$ of the total study subjects were Saudi nationals. This study concluded that Saudi Arabia has an increasing magnitude of true NTM diseases [38].

\section{Future milestones in controlling TB in Saudi Arabia}

In Saudi Arabia, basic, applied, and clinical research, plus implementations of new policies on TB control, are still not well progressed. The majority of the TB-related publications in the country are retrospective or population-based analyses targeted at the epidemiology or clinical manifestations of the disease. Data on basic or fundamental research related to TB in Saudi Arabia is almost nil in the arena of scientific literature. However, to date, only one national drug surveillance survey and two surveys on molecular epidemiology of drug-resistant and drugsusceptible $M$. tuberculosis isolates have been conducted $[21,39,40]$. There is an absolute necessity for many research focal points, particularly related to the socio-economic and host-related factors of TB and the impact of various $M$. tuberculosis strains and lineages on the outcome of treatment or clinical presentations.

\section{Qualitative research}

Non-adherence to the strategies of the WHO in performing case notification and DOTS remains high among TB patients, particularly in developing countries [1]. The reasons for such defiance have never been explored in Saudi Arabia [41]. The treatment outcome has never reached the $85 \%$ target set by the WHO, despite the implementation of DOTS in the early nineties. The treatment failure or default rate in the country was reported to be very high in previous studies, ranging from $13.23 \%$ to $30.6 \%$ $[42,43]$. However, recent nationwide published data is not available to assess the current status. There may be valid reasons causing such failures in the country. A recent report suggested some possibilities. These include the presence of $45 \%-48 \%$ of immigrant patients, the majority of whom are not well educated and unaware about the consequences of failure to complete the medications; the considerable proportion of illegal immigrants with TB who fear deportation; the lack of long-term support for most immigrants who live in the country without their families; social stigma about the disease; and fear about the lengthy hospitalization. Relevant qualitative research may be the missing link in successful TB control [41].
Figure 6: Nationwide species diversity of non-tuberculous mycobacteria in Saudi Arabia [38]

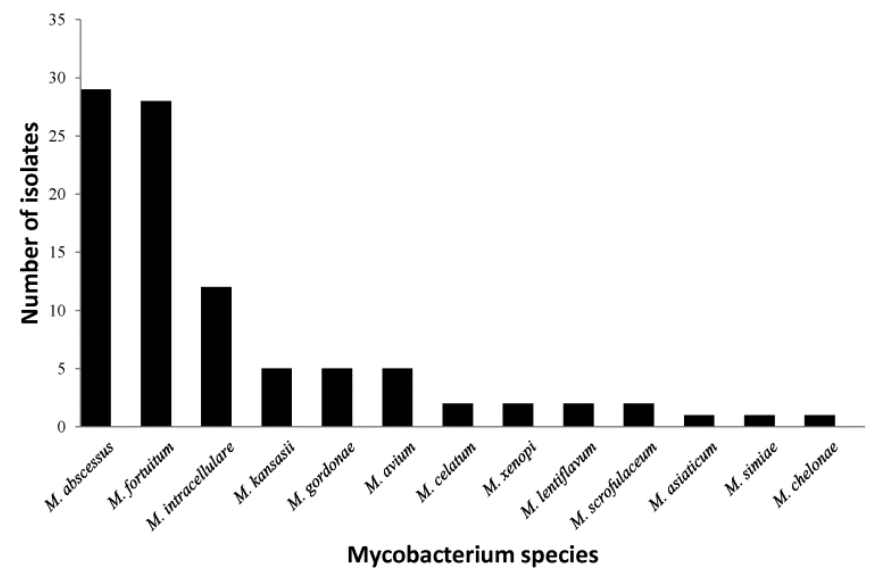

Therefore, immediate action is necessary to conduct a qualitative research to find the root causes of treatment non-compliance in Saudi Arabia.

\section{Need for a centralized advanced data registry}

Currently, the Ministry of Health reports each TB case from all the provinces with a unique TB code to the central data unit. However, the information collected as part of the standard reporting procedure does not include detailed profiles of the etiologies or patients. Thus, there are no data on genetic profiling or drug resistance of the isolates. Moreover, the registry does not offer free access to clinicians or patient care professionals. To improve the management of epidemiological data and patients' profiles, a central database or registry with easy access for clinicians who are actively involved in NTP is needed urgently [44]. A central TB registry has led to better infection control practices and patient care management in developed countries. Some of the best examples of central data registry are the European Tuberculosis Surveillance Network and various registries maintained by the United Kingdom, the United States, Germany, and the Netherlands, which can be adapted by Saudi Arabia and neighboring Arab countries. The registry should include drug susceptibility profiles, genotypic profile, patient demography, treatment, and clinical history. Such a system can avoid the duplication of registration of patients under NTP when they move from one province to another. Therefore, building a new registry that can be accessed via internet by the respective users in the NTP, particularly for physicians treating patients, is essential and highly recommended. 


\section{Need for a central referral research laboratory facility}

The country should have a national mycobacteria referral laboratory, which can be a key player in complicated interpretations in diagnosis and research. In addition, the referral laboratory can act as a place for research, training, and standardization of new diagnostic techniques. A regular external quality assurance program can be organized by the referral laboratory to all the TB diagnostic centers to maintain uniform standards and quality. The laboratory should be well equipped with updated technologies and should support the updates on centralized data registry. The model laboratory systems of the European Reference Laboratory Network for TB (ERLN-TB) and the South Asian Association for Regional Cooperation (SAARC) countries can be adapted for the Arabian peninsula, particularly for the Gulf Cooperation Council member states [45]. However, a well-equipped reference facility along with data registries are available in most developed countries such as Canada, the United States, the United Kingdom, Denmark, Germany, and the Netherlands. On the other hand, even developing countries in Africa (e.g., Uganda, Kenya, and South Africa) and Europe (e.g., Georgia, Lithuania) also have a national mycobacterial reference laboratory in place [1]. Thus the need for such a laboratory in Saudi Arabia is evident.

\section{Implementing technologies \\ modern diagnostic}

New technologies should be implemented to improve case notifications, rapid diagnosis, and treatment success. Although the country has moved forward with infrastructure development for the NTP, the incomplete target achievements in case notification and treatment shows the further need for improvements. Further to the phenotypic profiling of the causative agent of TB, M. tuberculosis, current research is focused on a genetic profiling, which enables effective use of the modern diagnostic and treatment schemes. Molecular techniques are more rapid and sensitive and have a shorter turnaround time. Detection and treatment of drug-resistant TB requires more attention. To facilitate and improve rapid diagnosis, particularly of drug-resistant TB, modern diagnostic techniques must be adapted to all the TB diagnostic facilities. Genome-based assays are more trusted and are becoming popular in the research field. Whole-genome-based techniques have proved to be the best source of information about the causative agents and can be used to draw up treatment regimens and to facilitate control measures.

\section{Exploring host related factors of mycobacterial susceptibility}

This is the most interesting development in the field of genetic research, as various host genetic susceptibility factors towards mycobacterial diseases have been explored in recent years. As a country with the highest rate $(58 \%)$ of consanguinity reported in the world and a prevalence of numerous genetic disorders, the potential of all the identified and unexplored genetic factors needs to be investigated [46,47]. Recent studies have shown that the indigenous population is affected by EPTB, NTM infections, BCG vaccine-related complications, and an upward trend of pulmonary tuberculosis [5,38]. The major assumption is that the Saudi population may have certain genetic susceptibilities towards mycobacterial diseases. Some of the factors that make people vulnerable to mycobacterial disease have already been reported from Saudi Arabia [48].

\section{Conclusions}

The consistent reporting of a moderate rate of $\mathrm{TB}$ in the last 10 years in Saudi Arabia highlights the need to exert more attention to its control and management $[5,9]$. The increasing mortality rate among the Saudi population, in contract to the steady state in the immigrants population, is a serious concern. The influx of millions of immigrant workers and pilgrims has a very high impact on TB transmission and the phylogeography of the causative agent. The poor implementation of control programs and failure to attain the WHO's global target shows the need for more vigorous strategies to be introduced and followed. The introduction and implementation of modern technologies and new research focal points are crucial, particularly analysis of population-based factors. The country urgently requires a central database or registry with phenotypic and genotypic profiles of the causative agent linked to patients' demographic data. This registry should be accessible to the treating clinicians and supportive members of the team to enable them to know the history of the patients in terms of treatment and drug resistance, and to look deeper into the genetic profile of the causative agent. This will help the clinicians to accurately diagnose the status of the disease (relapse/reactivation/reinfection) and continue with the right choice of drugs rather than administering empirical therapy. Whole-genome-based research is an 
absolute necessity that focuses on host-related factors, as the population has been found to harbor several mycobacterial susceptibility genetic factors. Timely data publications will increase knowledge and introduce more research focal points. Overall, the country needs an immediate strengthening in the current control policies, research and diagnostic facilities, properly trained manpower management, and adaptation to upcoming technologies.

\section{Acknowledgements}

We are thankful to Ms. Mary Grace Fernandez for her valuable support in the critical review of this manuscript.

\section{References}

1. World Health Organization (2013) Global Tuberculosis Report 2013. Geneva: WHO.

2. Saudi Arabia Central Department of Statistics and Information (2013) Statistical Year Book 1434. Riyadh: CDSI, KSA.

3. United Nations Statstics Division (2013) Millenium Development Goals Indicators.

4. Abouzeid MS, Al RF, Memish ZA (2013) Mortality among tuberculosis patients in Saudi Arabia (2001-2010). Ann Saudi Med 33: 247-252.

5. Abouzeid MS, Zumla AI, Felemban S, Alotaibi B, O'Grady J, Memish ZA (2012). Tuberculosis trends in Saudis and nonSaudis in the Kingdom of Saudi Arabia--a 10 year retrospective study (2000-2009). PloS one 7: e39478.

6. Varghese B, Supply P, Shoukri M, Allix-Beguec C, Memish Z, Abuljadayel N, Al-Hakeem R, AlRabiah F, Al-Hajoj S (2013) Tuberculosis transmission among immigrants and autochthonous populations of the eastern province of Saudi Arabia. PloS one 8: e77635.

7. Gleason JA, McNabb SJ, Abduljadayel N, Abouzeid MS, Memish ZA (2012) Tuberculosis trends in the Kingdom of Saudi Arabia, 2005 to 2009. Ann Epidemiol 22: 264-269.

8. Ministry of Health Saudi Arabia (2012) Statistical Book for the Year 1432. Riyadh, Saudi Arabia: MOH.

9. Al-Orainey I, Alhedaithy MA, Alanazi AR, Barry MA, Almajid FM (2013) Tuberculosis incidence trends in Saudi Arabia over 20 years: 1991-2010. Ann Thoracic Med 8: 148152.

10. Ministry of Health Saudi Arabia (2007) Statistical Book for the Year 1427. Riyadh, Saudi Arabia: MOH.

11. Al-Otaibi F, El Hazmi MM (2010) Extra-pulmonary tuberculosis in Saudi Arabia. Indian J Pathol Microbiol 53: 227-231.

12. Bukhary ZA, Alrajhi AA (2004) Extrapulmonary tuberculosis, clinical presentation and outcome. Saudi Med J 25: 881-285.

13. Qari FA (2002) The spectrum of tuberculosis among patients of the King Abdul Aziz Unveristy Hospital, Jeddah, Saudi Arabia. Southeast Asian J Trop Med Public Health 33: 331337.

14. Mokaddas E, Ahmad S, Samir I (2008) Secular trends in susceptibility patterns of Mycobacterium tuberculosis isolates in Kuwait, 1996-2005. Int J Tuberc Lung Dis 12: 319-325.
15. Forssbohm M, Zwahlen M, Loddenkemper R, Rieder HL (2008) Demographic characteristics of patients with extrapulmonary tuberculosis in Germany. European Respir J 31: 99-105.

16. Wilder-Smith A, Foo W, Earnest A, Paton NI (2005) High risk of Mycobacterium tuberculosis infection during the Hajj pilgrimage. Trop Med Int Health 10: 336-339.

17. Al-Orainey IO (2013) Tuberculosis infection during Hajj pilgrimage. The risk to pilgrims and their communities. Saudi Med J 34: 676-680.

18. Alzeer A, Mashlah A, Fakim N, Al-Sugair N, Al-Hedaithy M, Al-Majed S, Jamjoom G (1998) Tuberculosis is the commonest cause of pneumonia requiring hospitalization during Hajj (Pilgrimage to Makkah). J Infect 36: 303-306.

19. Al-Bishri J, Masoodi I, Adnan M, Tariq M, Abdullah H, Abdulgoni T, Bander G, Altalhi M (2014) Population dynamics and tuberculosis: a cross sectional study of an overlooked disease in Saudi Arabia. German Med Science J 12: Doc02.

20. Varghese B, al-Omari R, Grimshaw C, Al-Hajoj S (2013) Endogenous reactivation followed by exogenous re-infection with drug resistant strains, a new challenge for tuberculosis control in Saudi Arabia. Tuberculosis 93: 246-249.

21. Varghese B, Supply P, Allix-Beguec C, Shoukri M, Al-Omari R, Herbawi M, Al-Hajoj S (2013) Admixed phylogenetic distribution of drug resistant Mycobacterium tuberculosis in Saudi Arabia. PloS one 8: e55598.

22. Al-Hajoj S, Varghese B, Al-Habobe F, Shoukri MM, Mulder A, van Soolingen D (2013) Current trends of Mycobacterium tuberculosis molecular epidemiology in Saudi Arabia and associated demographical factors. Infect Genet Evol 16: 362368.

23. Al-Hajoj SA, Zozio T, Al-Rabiah F, Mohammad V, AlNasser M, Sola C, Rastogi N (2007) First insight into the population structure of Mycobacterium tuberculosis in Saudi Arabia. J Clin Microbiol 45: 2467-2473.

24. Alrajhi AA, Al-Barrak AM (2002) Mycobacterium tuberculosis susceptibility in Saudi Arabia. Saudi Med J 23: 1227-12231.

25. Ellis ME, al-Hajjar S, Bokhari H, Hussein Qadri SM (1996) High proportion of multi-drug resistant Mycobacterium tuberculosis in Saudi Arabia. Scand J Infect Dis 28: 591-595.

26. Kordy FN, Al-Thawadi S, Alrajhi AA (2004) Drug resistance patterns of Mycobacterium tuberculosis in Riyadh, Saudi Arabia. Int J Tuberc Lung Dis 8: 1007-10011.

27. Al-Rubaish AM, Madania AA, Al-Muhanna FA (2001) Drug resistance pulmonary tuberculosis in the Eastern Province of Saudi Arabia. Saudi Med J 22: 776-779.

28. Abu-Amero KK (2002) Status of antituberculosis drug resistance in Saudi Arabia 1979-98. East Mediterr Health J 8: 664-670.

29. Khan MY, Kinsara AJ, Osoba AO, Wali S, Samman Y, Memish Z (2001) Increasing resistance of Mycobacterium tuberculosis to anti-TB drugs in Saudi Arabia. Int J Antimicrob Agents 17: 415-418.

30. Varghese B, Al-Omari R, Al-Hajoj S (2013) Inconsistencies in drug susceptibility testing of Mycobacterium tuberculosis: Current riddles and recommendations. Int J Mycobacteriol 2: 14-17.

31. Varghese B, Hillemann A, Wijayanti DR, Shoukri M, Alrabiah F, Al-Omari R, Al-Hajoj S (2012) New insight into the molecular characterization of isoniazid and rifampicin 
resistant Mycobacterium tuberculosis strains from Saudi Arabia (2012). Infect Genet Evol 12: 549-56.

32. Varghese B, Shoukri M, Memish Z, Abuljadayel N, Alhakeem R, Alrabiah F, Al-Hajoj S (2014) Occurrence of diverse mutations in isoniazid- and rifampicin-resistant Mycobacterium tuberculosis isolates from autochthonous and immigrant populations of Saudi Arabia. Microbial Drug Resist 20: 623-631.

33. Mazroa MA, Kabbash IA, Felemban SM, Stephens GM, AlHakeem RF, Zumla AI, Memish ZA (2012) HIV case notification rates in the Kingdom of Saudi Arabia over the past decade (2000-2009). PloS one 7: e45919.

34. Alrajhi AA, Nematallah A, Abdulwahab S, Bukhary Z (2002) Human immunodeficiency virus and tuberculosis co-infection in Saudi Arabia. Eastern Mediterranean Health J 8: 749-753.

35. Omair MA, Al-Ghamdi AA, Alrajhi AA (2010) Incidence of tuberculosis in people living with the human immunodeficiency virus in Saudi Arabia. Int J Tuberc Lung Dis 14: 600-603.

36. Griffith DE, Aksamit T, Brown-Elliott BA, Catanzaro A, Daley C, Gordin F, Holland SM, Horsburgh R, Huitt G, Iademarco MF, Iseman M, Olivier K, Ruoss S, von Reyn CF, Wallace RJ Jr, Winthrop K; ATS Mycobacterial Diseases Subcommittee; American Thoracic Society; Infectious Disease Society of America (2007) An official ATS/IDSA statement: diagnosis, treatment, and prevention of nontuberculous mycobacterial diseases. Am J Respir Crit Care Med 175: 367-416.

37. Varghese B, Shajan SE, Al MO, Al-Hajoj SA (2012) First case report of chronic pulmonary lung disease caused by Mycobacterium abscessus in two immunocompetent patients in Saudi Arabia. Ann Saudi Med 32: 312-314.

38. Varghese B, Memish Z, Abuljadayel N, Al-Hakeem R, Alrabiah F, Al-Hajoj SA (2013) Emergence of clinically relevant Non-Tuberculous Mycobacterial infections in Saudi Arabia. PLoS Neglect Trop Dis 7: e2234.

39. Al-Hajoj SA, Zozio T, Al-Rabiah F, Mohammad V, AlNasser M, Sola C, Rastogi N (2007) First insight into the population structure of Mycobacterium tuberculosis in Saudi Arabia. J Clin Microbiol 45: 2467-2473.

40. Al-Hajoj S, Varghese B, Shoukri MM, Al-Omari R, AlHerbwai M, Alrabiah F, Abuljadayel N, Al-Thawadi S, Zumla A, Zignol M, Raviglione MC, Memish Z (2013) Epidemiology of antituberculosis drug resistance in Saudi Arabia: findings of the first national survey. Antimicrob Agent Chemother 57: 2161-2166.

41. Al-Hajoj S, Varghese B (2013) Qualitative research: Is this a missing link to control tuberculosis in Saudi Arabia? Int $\mathbf{J}$ Mycobacteriol 2: 126-127.
42. Samman Y, Krayem A, Haidar M, Mimesh S, Osoba A, AlMowaallad A, Abdelaziz M, Wali S (2003) Treatment outcome of tuberculosis among Saudi nationals: role of drug resistance and compliance. Clin Microbiol Infect 9: 289-294.

43. Al-Hajjaj MS (2000) The outcome of tuberculosis treatment after implementation of the national tuberculosis control program in Saudi Arabia. Ann Saudi Med 20: 125-128.

44. Crawford JT, Braden CR, Schable BA, Onorato IM (2002) National Tuberculosis Genotyping and Surveillance Network: design and methods. Emerg Infect Dis 8: 1192-1196.

45. Drobniewski FA, Nikolayevskyy V, Hoffner S, Pogoryelova O, Manissero D, Ozin AJ (2008) The added value of a European Union tuberculosis reference laboratory network-analysis of the national reference laboratory activities. Euro Surveill 13. pii: 8076.

46. El Mouzan MI, Al Salloum AA, Al Herbish AS, Qurachi MM, Al Omar AA (2008) Consanguinity and major genetic disorders in Saudi children: a community-based crosssectional study. Ann Saudi Med 28: 169-173.

47. el-Hazmi MA, al-Swailem AR, Warsy AS, al-Swailem AM, Sulaimani R, al-Meshari AA (1995) Consanguinity among the Saudi Arabian population. J Med Genet 32: 623-626.

48. Prando C, Samarina A, Bustamante J, Boisson-Dupuis S, Cobat A, Picard C, AlSum Z, Al-Jumaah S, Al-Hajjar S, Frayha H, Alangari A, Al-Mousa H, Mobaireek KF, BenMustapha I, Adimi P, Feinberg J, de Suremain M, Jannière L, Filipe-Santos O, Mansouri N, Stephan JL, Nallusamy R, Kumararatne DS, Bloorsaz MR, Ben-Ali M, Elloumi-Zghal H, Chemli J, Bouguila J, Bejaoui M, Alaki E, AlFawaz TS, Al Idrissi E, ElGhazali G, Pollard AJ, Murugasu B, Wah Lee B, Halwani R, Al-Zahrani M, Al Shehri MA, Al-Zahrani M, BinHussain I, Mahdaviani SA, Parvaneh N, Abel L, Mansouri D, Barbouche R, Al-Muhsen S, Casanova JL (2013) Inherited IL-12p40 deficiency: genetic, immunologic, and clinical features of 49 patients from 30 kindreds. Medicine 92: 109122.

\section{Corresponding author}

\section{Sahal Al-Hajoj}

Mycobacteriology Research Section, Department of Infection and Immunity, King Faisal Specialist Hospital and Research Centre, Takasusi Street, PB No-3354

Riyadh, 11211, Saudi Arabia

Phone: 00966-1-4432599

Fax: 00966-1-4627858

Email: hajoj@kfshrc.edu.sa

Conflict of interests: No conflict of interests is declared. 